\title{
25 Research Square \\ Could China's Long-term Low-carbon Energy Transformation Achieve the Double Dividend Effect for the Economy and Environment?
}

\section{Ling $\mathrm{He}$}

Beijing Normal University

\section{Bangpei Wang}

Beijing Normal University

Wanting Xu

Beijing Normal University

Qi Cui

Beijing Normal University

Hao Chen ( $\square$ hchen@bnu.edu.cn )

Beijing Normal University

\section{Research Article}

Keywords: low-carbon transformation, economic impact, environmental impact, carbon peak, carbon neutrality, China

Posted Date: July 16th, 2021

DOI: https://doi.org/10.21203/rs.3.rs-590792/v1

License: @ (1) This work is licensed under a Creative Commons Attribution 4.0 International License. Read Full License

Version of Record: A version of this preprint was published at Environmental Science and Pollution Research on November 2nd, 2021. See the published version at https://doi.org/10.1007/s11356-021-17202-1. 


\section{Abstract}

Achieving low-carbon energy transformation is vital for coordinating economic growth and environmental improvement to satisfy the carbon emissions peak and carbon neutrality targets. Existing studies, however, have been dominated by the mere exploration of the low-carbon transformation pathway with little consideration of the importance of energy substitution in low-carbon transformation. Doing so is believably unable to gain the double dividend effect for the economy and environment. Accordingly, this paper develops three energy-target scenarios, taking into account energy structure, electrification level, and carbon mitigation targets by 2030 announced by the Chinese government. A dynamic multi-sectoral computable general equilibrium model, CHINAGEM, is employed to examine the economic and environmental effects under different pathways of long-term low-carbon transformation. Firstly, we detect that China's primary energy consumption and electricity production structure would substantially transfer to low-carbon and clean along with all three energy-target scenarios. Secondly, due to the anticipated decline of fossil energy consumption, especially coal consumption, China's $\mathrm{CO}_{2}, \mathrm{SO}_{2}$, and $\mathrm{NO}_{X}$ emissions in 2020-2030 would also possibly vastly abate with all the scenarios. Besides, it is highly conceivable for China to achieve its peak carbon emission of $12.4 \mathrm{GtCO}_{2}$ in 2028 if it serves the comparatively more stringent low-carbon transformation pathways. Lastly, different pathways would also produce varying positive impacts on China's macro-economy and achieve the different extent of double dividend effects. The research concludes with a recommendation of tentative improvement policies towards low-carbon transformation under the carbon peak and carbon neutrality goals, including promoting energy substitution, renewable energy development, and low-carbon technologies.

\section{Introduction}

Low-carbon development, a chief means to mitigate global warming, has led the world economic development trend. The excessive use of fossil energy has led to a continuous increase in global carbon emissions and environmental pollution (Zhou et al., 2019; Rajbhandari and Limmeechokchai, 2020; Monjardino et al., 2021). As the world's most enormous energy consumer and producer, China has increasing international pressure to control its rising greenhouse gas emissions and protect the environment (Liu et al., 2017; Wang et al., 2019). In 2014, China committed to reaching its carbon dioxide $\left(\mathrm{CO}_{2}\right)$ emissions peak by 2030 or earlier and increasing the share of nonfossil fuels in total energy consumption to $20 \%$ by 2030 . In the Nationally Determined Contribution of the Paris Agreement framework, China reiterated the above commitments and proposed to reduce carbon intensity by $60-65 \%$ from 2005 levels by 2030. China successively proposed the "13th Five-Year Energy Development Plan" (NDRC, 2016a) and "Energy Production and Consumption Revolution Strategy (2016-2030)" (NDRC, 2016b), which clearly stated the future energy transformation pathway by reducing fossil energy consumption and carbon emissions. With the proposal of carbon neutrality commitment by 2060 (Mallapaty, 2020; Su and Urban, 2021), it is urgent and necessary to accelerate China's long-term low-carbon energy transformation (Huang and Zhai, 2021; Zhou et al., 2021).

To keep the above energy targets within the planned scope, achieving low-carbon energy transformation would profoundly affect the Chinese economy (Li et al., 2019; Lv and Xu, 2019). Traditional energy has supported China's economic growth in the past decades. However, the environmental destruction and the limited fossil fuel resource endowment pose growing challenges (Dai et al., 2016; Mittal et al., 2016; Su and Urban, 2021). Some studies projected that carbon emissions would exceed $18 \mathrm{GtCO}_{2}$ by 2030 if China keeps the current energy structure and economic development pattern (Chi et al., 2014; Duan et al., 2018). However, strengthening environmental protection and accelerating emissions mitigation will increase industries' costs and even cause economic losses (Wang and Chen, 2019). Therefore, it is worth exploring whether and how China's low carbon transformation could achieve the 
double dividend effect for both economic growth and environmental improvement, which is vital to achieving ambitious goals of carbon peak and carbon neutrality.

Despite increasing efforts laid on the relationship between China's economic growth and environmental improvement, existing studies have not reached an agreement. Most scholars insisted that economic growth and environmental protection are not mutually beneficial. Some argued that accelerating emissions mitigation would hinder a country's economic development (Shi et al., 2014; Dai et al., 2016; Mi et al., 2017; Cui et al., 2019; Yuan et al., 2020). Based on the input-output model, Mi et al. (2017) estimated that China's carbon emissions would peak at 11.2 Gt in 2026, while its cumulative GDP would reduce by $16.45 \%$. Dai et al. (2016) assessed that the large-scale development of renewable energy causes the GDP to decrease by $0.27 \%$ but brings substantial environmental benefits. Shi et al. (2014) used the Dynamic CGE model to find that China's energy consumption and $\mathrm{CO}_{2}$ emissions would decrease significantly, but the GDP growth rate after 2020 would drop by $0.6-0.7 \%$.[CQ1] The others argued that the economy could maintain a growth trend under the current energy development pathway, but the carbon and pollutant emissions would also increase considerably. Li et al. (2019) pointed out that the rapid economic growth in China has significantly deteriorated environmental pollution. Chen et al. (2019) predicted that China's economy could still grow stably during the 13th Five-Year Plan period, while the total energy consumption and carbon emissions will maintain a high level. Wu and Fan (2017) asserted that China's economic growth before 2030 would raise the growth rate of $\mathrm{CO}_{2}$ emissions, which would eventually hinder China's sustainable development in the long term. According to the existing literature, achieving a balance between controlling carbon emissions and maintaining economic growth is a common challenge for China (Xiong and Xu, 2021). Therefore, this paper aims to explore how China's low-carbon transformation achieves the synergy of the economic and environmental effects.

Since China proposed the ambitious target of carbon peaking and carbon neutrality, most scholars have attempted to explore the low-carbon transformation by investigating two types of pathways, including developing renewable energy and reducing carbon emissions. Some studies demonstrated that China could achieve carbon emission mitigation and significantly reduce GDP loss by adopting policies for renewable energy development (Duan et al., 2018; Ma, 2019). Other studies examined the effectiveness of taking more stringent emission reduction measures by constraining the scale of GDP and improving energy efficiency (Liu et al., 2018; Mi et al., 2017; Yu et al., 2018). Moreover, few researchers suggested that if China follows a pathway aggressively adopting emission reduction technologies while increasing renewable resources, it can achieve its carbon emission mitigation targets (He and Lin, 2018; Li et al., 2018; Zhou et al., 2019). However, these studies have not explicitly assessed the role of improving the electrification level by fostering energy substitution. Due to the different carbon emission intensity, the substitution of coal with non-fossil energy and coal-fired electricity with non-fossil electricity could effectively reduce carbon emissions without reducing total energy consumption (Chen et al., 2019; Khanna et al., 2019; Lin and Agyeman, 2019). Unlike previous researches that only focused on adopting $\mathrm{CO}_{2}$ mitigation measures and renewable energy development, this study develops three scenarios, representing various low-carbon transformation pathways, to figure out which pathway could achieve the most beneficial synergistic effect for the economy and environment.

The literature mentioned above provides us with valuable references for understanding the economic and environmental effects of low-carbon transformation pathways, but they are also subject to limitations. Firstly, existing studies have failed to explore whether the pathways of low-carbon transformation could achieve the double dividend effects for the economy and environment. Secondly, the scenarios representing the pathways of low-carbon transformation primarily focused on renewable energy development and low-carbon technology while rarely considered the potential of energy substitution. 
We design three energy-target scenarios to narrow the research gaps, taking energy structure optimization, electrification, and carbon mitigation targets into consideration. After that, a dynamic Computable General Equilibrium (CGE) model, CHINAGEM, is applied to compare the economic and environmental implications among different pathways of China's low-carbon transformation. The main contributions of this study are as follows. 1) This paper reveals the long-term relationship between the economy and environment under differentiated low-carbon transformation pathways. 2) The paper explores which low-carbon transformation pathway could achieve a doubledividend effect of economic growth and environmental improvement. 3) Distinguishing from the previous literature, the study considers the role of energy substitution for the low-carbon transformation. We expect to provide some practical suggestions for China to harmonize the development of the economy and environment in low-carbon transformation, contributing to the carbon-emissions peak and carbon neutrality trajectories.

The rest of this paper arranges as follows. Section 2 introduces the simulation model and scenario setting. Section 3 compares the impacts on the energy structure, $\mathrm{CO}_{2}$ and pollutant emissions, and macro-economy used by the CHINAGEM model among the scenarios with different energy targets. Section 4 and Sect. 5 introduces the discussions and concludes the paper with policy implications.

\section{Simulation Model And Scenario Setting 2.1 CHINAGEM Model}

This paper uses a dynamic multi-sectoral CGE model, CHINAGEM, to simulate and compare the economic and environmental impacts among the scenarios with different energy targets. The CHINAGEM model, developed by the Center of Policy Studies at Victoria University, is applied widely to evaluate various energy policies (Cui et al., 2021; Cui et al., 2020; Chen et al., 2019; Li et al., 2018). The CHINAGEM model comprises a series of mathematical equations, which describe the economic activities of sectoral production, household consumption, investment, export, and equilibrium. We, to save the illustration space, introduce only the nested structure of energy commodities consumed by production sectors in the CHINAGEM model.

According to the principle of cost minimization, the producers determine their optimal inputs (Fig. 1). On top of the nested structure of energy products for production sectors, the total output is produced from various inputs (nonenergy intermediate inputs, composited energy commodity, and composited primary factor input) based on the Leontief function. At the lower level, the energy commodity is the combination of electricity and fossil-fuel energy depicted by the constant elasticities of substitution (CES) function, with the substitution elasticity of 0.16 . Then, fossil-fuel energy consists of coal energy and petroleum and gas energy using the CES function with the substitution elasticity of 0.5 . On the bottom, coal branches into crude coal and coke described by the CES function with a substitution elasticity of 0.25 , and the commodity of petroleum and gas energy into crude oil, natural gas, petroleum product, and gas supply.

The electricity sector decomposes into eight electricity generation sectors with different power sources and one sector for electricity transmission and distribution (Fig. 2). The electricity sectors include coal-fired power, oil-fired power, gas-fired power, nuclear power, hydropower, wind power, solar power, biomass, and geothermal power. The Leontief function takes on top of the nested structure, assuming that electricity consumption is fixed proportionally to electricity transmission and distribution. Then, we categorize electricity sectors into stable and intermittent electricity, adopting the CES function with the substitution elasticity of 3. Following Cui et al. (2020) and Mu et al. (2018), stable electricity includes coal-fired power, oil-fired power, gas-fired power, nuclear power, hydropower, and biomass and geothermal power. The model sets their substitution elasticity value to 5 using the CES function. The 
intermittent electricity consists of wind power and solar power, depicted by the CES function with a substitution elasticity of 3 .

\subsection{Data and Closure}

This paper employs China's input-output table of 2012 with 139 production sectors as the model's database. To predict and analyze the energy structure under different scenarios, we split the original electricity sector and crude oil and gas sector in detail following the method of Cui et al. (2020). Thus, the CHINGEM model in this paper contains 146 production sectors (Table A1, Appendix A). The Armington elasticities and other elasticities like demand elasticity and supply elasticity are mainly from the Global Trade Analysis Project V9 database and Mai et al. (2010). The model calculates the energy-related $\mathrm{CO}_{2}$ emissions by multiplying the production sectors' and households' coal consumption, natural gas, crude oil, and petroleum products with their corresponding $\mathrm{CO}_{2}$ emission factors from IPCC (2006). It is worth noting that this paper does not consider the $\mathrm{CO}_{2}$ emissions during production and conversion processes. The same approach applies to calculating the energy-related emissions of sulfur dioxide $\left(\mathrm{SO}_{2}\right)$ and nitrogen dioxide $\left(\mathrm{NO}_{X}\right)$ without considering the emission control technology till 2030.

For the dynamic simulation of the CHINAGEM model, this paper adopts short-term macro-economic closure for each year. Specifically, because of the almost fixed nominal wage contracts, the wages assumedly remain fixed, while the employment of production sectors determined by real wages. The capital of the production sectors assumedly remains fixed, and the return of capital is allowed to change. The rate of return determines the investment of each production sector. The government expenditure fixes in proportion to household expenditure.

\subsection{Simulation Scenario Design}

This paper constructs a baseline scenario and three energy-target scenarios to investigate the economic and environmental implications by different pathways of China's low-carbon transformation. We refer to the projection on China's energy production and consumption in the $\mathrm{IE}_{2} 018$ reference case $(E I A, 2018)$ for establishing the baseline scenario, holding the policies and regulations unchanged under the current technological progress, economic growth, and population structure.

Scenario 1. As the "Energy Production and Consumption Revolution Strategy (2016-2030)" (NDRC, 2016b) and the "13th Five-Year Energy Development Plan" (NDRC, 2016a) outlined the roadmap of future energy transformation in China, the targets of energy structure, electrification level, and carbon mitigation are specified (Table 1). This scenario specifies a foundation pathway of low-carbon energy transformation, shifting the energy structure to nonfossil energy with various policies. For the energy structure target, by 2030 , total energy consumption is controlled within 6,000 Mtce. The proportion of non-fossil energy consumption will increase to a level of $20 \%$; the proportion of non-fossil fired power in total power generation will exceed $50 \%$. Satisfying the electrification level target requires the terminal energy of major energy consumers (the construction and transportation sectors) to reach an electrification rate of $25 \%$ by 2030 . For carbon mitigation target, China's carbon emission intensity will decrease by $18 \%$ in $2020-$ 2030. 
Table 1

Summaries of scenario design

\begin{tabular}{|c|c|c|c|}
\hline & Scenario 1 & Scenario 2 & Scenario 3 \\
\hline $\begin{array}{l}\text { Energy } \\
\text { structure } \\
\text { targets }\end{array}$ & $\begin{array}{l}\text { 1. By } 2030 \text {, total energy } \\
\text { consumption is controlled } \\
\text { within } 6,000 \text { Mtce, and the } \\
\text { proportion of non-fossil energy } \\
\text { consumption will increase to } \\
20 \% \text {. } \\
\text { 2. By } 2030 \text {, the proportion of } \\
\text { non-fossil fired power in total } \\
\text { power generation will exceed } \\
50 \% \text {. }\end{array}$ & Same as Scenario 1. & Same as Scenario 2. \\
\hline $\begin{array}{l}\text { Electrification } \\
\text { level targets }\end{array}$ & $\begin{array}{l}\text { By } 2030 \text {, the electrification rates } \\
\text { in terminal energy of major } \\
\text { energy consumers (the } \\
\text { construction and transportation } \\
\text { sectors) will reach } 25 \% \text {. }\end{array}$ & $\begin{array}{l}\text { By } 2030 \text {, the electrification } \\
\text { rates in terminal energy } \\
\text { consumption of all } \\
\text { production sectors and } \\
\text { households will increase to } \\
30 \% \text {. }\end{array}$ & Same as Scenario 2. \\
\hline $\begin{array}{l}\text { Carbon } \\
\text { mitigation } \\
\text { targets }\end{array}$ & $\begin{array}{l}\text { In } 2020-2030 \text {, China's carbon } \\
\text { emission intensity will decrease } \\
\text { by } 18 \% .\end{array}$ & Same as Scenario 1. & $\begin{array}{l}\text { By } 2030 \text {, China will reduce } \\
\text { its carbon intensity from the } \\
2005 \text { level by } 60-65 \% \text {, and } \\
\text { achieve the carbon } \\
\text { emissions peak or earlier. }\end{array}$ \\
\hline
\end{tabular}

Scenario 2. The China Renewable Energy Outlook (ERI \& CNREC, 2017; 2018) proposed an energy target with a higher electrification level, covering more sectors to accelerate China's low-carbon transformation. Scenario 2 describes an advanced pathway of China's low-carbon transformation, which shifts its energy structure to electricity by raising the portion of electricity and natural gas and reducing the coal and crude oil consumption. Scenario 2 holds the exact specification as scenario 1 on energy structure target and carbon mitigation target, except for the electrification level target that requires the electrification rates in terminal energy consumption of households and all production sectors to increase to $30 \%$ by 2030 .

Scenario 3. Considering China's commitment to peak its carbon emissions in the Paris Agreement, this scenario depicts a more stringent low-carbon transformation pathway by adopting carbon mitigation measures. Scenario 3 shares the identical specification as scenario 2 on the energy structure target and electrification level target. Nevertheless, China needs to reduce its carbon intensity from 2005 levels by $60-65 \%$ and peak its carbon emissions peak by 2030 or earlier. To achieve this goal, it requires more ambitious actions to decarbonize the power sectors (e.g., reducing fossil-fired power generation and improving renewable power generation) and restrict natural gas consumption considering the energy substitution.

\section{Simulation Results}

\subsection{Energy consumption and electricity production in China}

Fig. 3 shows that China's total primary energy consumption would have a long-term low-speed growth stage under all three energy-target scenarios. Under the baseline scenario, China's total primary energy consumption will increase rapidly from 4,910 Mtce in 2020 to 7,919 Mtce in 2030, with an average annual growth rate of 4.90\%. However, the growth rate is predictively slow, and China's total primary energy consumption in 2030 projects to be 5,795, 5,770, 
and 5,761 Mtce under scenario 1, scenario 2, and scenario 3, respectively. These results are consistent with the Chinese government's energy targets for total energy consumption by 2030 . Compared with the 2020 level under these three scenarios, total primary energy consumption in 2030 is projected to increase with the average annual growth rate of $2.07 \%, 2.15 \%$, and $2.10 \%$, respectively.

From the perspective of energy consumption structure, China's primary energy consumption structure would substantially transfer to low-carbon and clean under all three target scenarios. Although the structure of China's primary energy consumption remains dominated by coal consumption in 2020-2030 under the three energy-target scenarios (i.e., accounting for more than $50 \%$ ), the share of coal consumption decreases gradually, with its withdrawn part to be substituted by non-fossil energy. Under the baseline scenario, the share of coal consumption is $60.5 \%$, but the non-fossil energy is only $15.2 \%$ in 2030 . It indicates that the energy consumption structure not under the pathway of low-carbon transformation is inconsistent with the Chinese government's energy targets. Compared with the baseline scenario, the share of coal consumption would drop to $52.9 \%, 52.4 \%$, and $51.9 \%$ by 2030 , while the share of non-fossil energy predictably rises to $20.1 \%, 20.5 \%$, and $21.5 \%$, respectively. Specifically, affected by energy substitution and decarburization in power sectors, coal consumption in China predictively decreases (decrease by 1798Mtce compared with baseline scenario) most dramatically in scenario 3. However, natural gas and non-fossil energy consumptions increase sharply (increase by 226Mtce) by 2030.

\subsubsection{Electricity production}

It suggests that total electricity production in China predictively increases rapidly in the long term under all three energy-target scenarios (Fig. 4). Under the baseline scenario, China's total power generation would increase from 7,540 TWh in 2020 to 12,979 TWh in 2030 , with an average annual growth rate of $5.58 \%$, mainly driven by the increase in coal-fired electricity demand. By 2030, China's total power generation declines to $12,056,12650$, and 12,401 TWh under scenario 1, scenario 2 , and scenario 3, respectively, corresponding to the average growth rates of $5.17 \%, 5.43 \%$, and $5.28 \%$. In 2030 , the total power generation under scenario 3 is predictively lower than under scenario 2 to some extent. The reason is the predicted reduction in electricity generation attributable to the dramatic pressure of carbon emissions reduction.

In terms of fuel types, the electricity production structure is assumedly clean and low-carbon during 2020-2030 under the three scenarios with different targets. It is reflective that the share of non-fossil power generation in the total electricity generation would increase, in companion with the coal-fired electricity portion decreasing across all the scenarios. Under the baseline scenario, coal is the primary electricity generation source, accounting for $50.6 \%$ of electricity generated in 2030 , while non-fossil energy power generation will only account for $44.4 \%$. Compared with the baseline scenario, the electricity structure is relatively cleaner. With the three energy-target scenarios, the coal-

fired power generation's share declines to $44.8 \%, 46.0 \%$, and $42.4 \%$ in 2030 , respectively. In contrast, the share of nonfossil power generation would gradually increase to $51.6 \%, 50.6 \%$, and $54.2 \%$ in 2030 under the same three scenarios, respectively. The rapid increase in the non-fossil electricity share is attributable to the rapid increase in non-fossil energy consumption by its downstream sectors. Under scenario 3 , the share of non-fossil power generation predictively increases dramatically because of the dramatic reduction in carbon emissions.

\subsection{Impacts on the environment}

\subsubsection{Impacts on carbon emissions}

Table 2. China's total carbon emissions and $\mathrm{CO}_{2}$ intensity in 2020-2030 under different scenarios 


\begin{tabular}{|c|c|c|c|c|c|c|c|c|}
\hline & \multicolumn{2}{|c|}{ Baseline Scenario } & \multicolumn{2}{|c|}{ Scenario 1} & \multicolumn{2}{|c|}{ Scenario 2} & \multicolumn{2}{|c|}{ Scenario 3} \\
\hline & $\begin{array}{l}\text { Total } \\
\left(\mathrm{GtCO}_{2}\right)\end{array}$ & $\begin{array}{l}\text { Intensity(per } \\
\text { unit of } \\
\text { GDP) }\end{array}$ & $\begin{array}{l}\text { Total } \\
\left(\mathrm{GtCO}_{2}\right)\end{array}$ & $\begin{array}{l}\text { Intensity(per } \\
\text { unit of } \\
\text { GDP) }\end{array}$ & $\begin{array}{l}\text { Total } \\
\left(\mathrm{GtCO}_{2}\right)\end{array}$ & $\begin{array}{l}\text { Intensity(per } \\
\text { unit of } \\
\text { GDP) }\end{array}$ & $\begin{array}{l}\text { Total } \\
\left(\mathrm{GtCO}_{2}\right)\end{array}$ & $\begin{array}{l}\text { Intensity (per } \\
\text { unit of } \\
\text { GDP) }\end{array}$ \\
\hline 2020 & 12.6 & 1.281 & 10.7 & 1.093 & 10.5 & 1.075 & 10.4 & 1.068 \\
\hline 2021 & 13.1 & 1.259 & 11.1 & 1.073 & 10.8 & 1.046 & 10.7 & 1.036 \\
\hline 2022 & 13.7 & 1.238 & 11.5 & 1.052 & 11.1 & 1.019 & 11.0 & 1.005 \\
\hline 2023 & 14.2 & 1.216 & 11.9 & 1.027 & 11.4 & 0.991 & 11.2 & 0.973 \\
\hline 2024 & 14.7 & 1.194 & 12.2 & 1.002 & 11.7 & 0.963 & 11.5 & 0.942 \\
\hline 2025 & 15.1 & 1.171 & 12.6 & 0.979 & 12.0 & 0.939 & 11.7 & 0.912 \\
\hline 2026 & 15.7 & 1.151 & 12.9 & 0.957 & 12.3 & 0.915 & 11.9 & 0.885 \\
\hline 2027 & 16.2 & 1.130 & 13.3 & 0.938 & 12.6 & 0.896 & 12.2 & 0.862 \\
\hline 2028 & 16.6 & 1.108 & 13.7 & 0.921 & 13.0 & 0.878 & 12.4 & 0.839 \\
\hline 2029 & 17.1 & 1.089 & 14.2 & 0.904 & 13.3 & 0.863 & 12.4 & 0.798 \\
\hline 2030 & 17.7 & 1.071 & 14.6 & 0.890 & 13.7 & 0.850 & 12.3 & 0.758 \\
\hline
\end{tabular}

Source: CHINAGEM model

The result shows that China's total carbon emissions would increase with a relatively low speed during 2020-2030 under the three energy-target scenarios (Table 2). Under the baseline scenario, China's total carbon emissions will increase from $12.6 \mathrm{GtCO}_{2}$ in 2020 to $17.7 \mathrm{GtCO}_{2}$ in 2030 , with an average annual growth rate of $3.44 \%$. Compared with the baseline scenario, the total carbon emissions under the three scenarios expect to reduce significantly by $14.6,13.7$, and $12.3 \mathrm{GtCO}_{2}$ in 2030 , respectively, with the average annual growth rate of $3.18 \%, 2.70 \%$, and $1.64 \%$, respectively. It reflects the low-carbon energy transformation would has a positive effect on carbon emissions reduction. In scenario 1 , China would have $3.1 \mathrm{GtCO}_{2}$ of total carbon emissions reduction in 2030 , suggesting that the fundamental pathway of energy transformation could slightly cut down China's total $\mathrm{CO}_{2}$ emissions when reducing the fossil energy consumption and increasing the electrification rate of some energy-consuming sectors. In Scenario 2. China's $\mathrm{CO}_{2}$ emissions will have a further reduction of $0.9 \mathrm{GtCO}_{2}$ in 2030 through increasing electricity demand and reducing coal and crude oil consumption by accelerating electrification. More importantly, it is worth mentioning that if China follows a more stringent pathway by taking carbon mitigation measures in Scenario 3, China's carbon emission peak would be achievable in 2028 , with $12.4 \mathrm{GtCO}_{2}$.

From the carbon-emission intensity perspective, China's carbon emission per unit of GDP decreases rapidly under the various energy-target scenarios. Under the baseline scenario, the carbon emission intensity would decrease from 1.281 tons in 2020 to 10.71 tons per unit of GDP in 2030, with an annual decline rate of $1.77 \%$. The results are inconsistent with the Chinese government's energy targets for carbon emission intensity by 2030. Compared with the baseline scenario, the carbon emission intensity would sharply decrease to 14.6, 13.7, and 12.3 tons in 2030 under the three energy-target scenarios, respectively. In scenarios 1 and 2, China's carbon emission intensity would achieve the grand goal of reducing $18 \%$ in $2020-2030$, yet it only reduces by $58.2 \%$ and $59.4 \%$ compared with the 2005 levels, respectively. Notably, the carbon emission intensity expects to commit its target of reducing the carbon intensity by $60-65 \%$ in scenario 3 (64.3\%). This is mainly driven by two factors: the energy-consumption structural optimization 
and the energy consumption per unit of GDP reduction. From the above results, we could find that the more stringent pathway of low-carbon transformation would have the most $\mathrm{CO}_{2}$ emissions reduction effect.

\subsubsection{Impacts on $\mathrm{SO}_{2}$ and $\mathrm{NO}_{x}$ emissions}

With the decline of fossil energy consumption, especially coal consumption, China's $\mathrm{SO}_{2}$ and $\mathrm{NO}_{\mathrm{x}}$ emissions in 20202030 would reduce largely under the three energy-target scenarios. It means that low-carbon energy transformation could effectively reduce the pollutant emissions, especially the more stringent pathway of low-carbon transformation in scenario 3 (Fig. 5).

Under the baseline scenario, the $\mathrm{SO}_{2}$ and $\mathrm{NO}_{\mathrm{X}}$ emissions would increase rapidly from 57.5 and 37.9 million tons in 2020 to 73.2 and 45.5 million tons in 2030 , respectively, with an average annual growth rate of $2.45 \%$ and $1.84 \%$. Compared with the baseline scenario, the increase in non-fossil energy consumption in scenario 1 would substantially reduce $\mathrm{SO}_{2}$ and $\mathrm{NO}_{x}$ pollutants. In $2030, \mathrm{SO}_{2}$ and $\mathrm{NO}_{X}$ emissions would decrease to 48.2 million tons and 30.0 million tons, smaller than those under the baseline scenario. The changes in $\mathrm{SO}_{2}$ and $\mathrm{NO}_{\mathrm{x}}$ emissions under scenario 2 would be similar to those under Scenario 1, causing a difference of only about 3.0 million tons. Although the higher electrification level would reduce the coal and crude oil consumption and increase the electricity consumption, the emissions caused by the increase in coal-fired electricity consumption would partly offset the emission reduction driven by the decrease in fossil energy. It suggests that the pollutant emissions reduction affected by the higher electrification level is slight. In scenario $3, \mathrm{SO}_{2}$ and $\mathrm{NO}_{\mathrm{x}}$ emissions begin to have downward trends during 2020-2030, with an average annual decline rate of $0.5 \%$ and $1.34 \%$. This energy pathway of low-carbon transformation reduces pollutant emissions remarkably by further reducing fossil energy consumption while increasing non-fossil electricity production.

\subsection{Impacts on Macro-economy}

In addition to the positive impacts on the environment, scenarios with different energy targets would also have significant positive impacts on China's macro-economy. Affected by the advancement of non-fossil energy and electricity generation technology, the outputs of non-fossil energy and all types of electricity would increase, which would raise total employment by $1.410-1.834 \%$, thereby contributing to an increase in real GDP by $0.791-1.233 \%$ from 2020 to 2030 . When considering the three targets of energy structure, higher electrification, and carbon emissions peak with the more stringent pathway of low-carbon transformation, China's economy tends to experience the most rapid increase. The employment in the labor market and real GDP would increase by $1.834 \%$ and $1.233 \%$ during 2020-2030.

Economic growth and increased energy demand would cause household consumption and government spending to increase by $0.984-1.623 \%$ and $0.982-1.682 \%$, respectively. The decline in fossil energy consumption leads to a reduction in the prices of energy-intensive investment commodities, entailing the investment consumption to rise by 0.807-1.294\%. The clean energy supply and demand structure will shorten the demand for fossil fuels. However, the increase in household income and consumption would drive an escalation in Consumer Price Index (CPI). Consequently, the rising CPI would further worsen China's trade terms, resulting in a decrease of $0.797-1.028 \%$ in exports and an increase in imports of $0.366-0.549 \%$.

\section{Discussion}

\subsection{The attainability and significance of the double dividend effect}

Page 9/19 
The study constructs purposefully three explorative energy-target scenarios to investigate whether and how surely the various low-carbon energy transformation pathways for China would produce a harmonized effect with double dividend on economic growth and environmental improvement. It manifests that all the three possible scenarios reflecting the nation's devotion to transforming the energy consumption structure in response to low-carbon development would lead to the fulfillment of the doubled dividends for the economy and environment, verifying the central query of this study.

The results show the double dividend effect would boost the economy by elevating the real GDP by $0.791-1.233 \%$ while driving the total employment to rise by $1.4101 .834 \%$ from $2020-2030$. The effect illustrates its particular significance to the economy. That is, the low-carbon energy transformation could notably benefit economic growth, stabilize labor employment, and escalate society's economic welfare. It is notable that except for the term of exports, all the other terms involving GDP, employment, investment, household consumption, government spending, imports, and consequently CPI are all going up. Such a trend infers that this period's macro-economy would step into an upbooming cycle with the low-carbon transformation. The predicted drop in exports may imply the advent of a more balanced trade and market structure that simulates domestic consumption while allowing more foreign products and services to enter China's market with reinforced openness, along with the low-carbon transformation.

Besides, China's $\mathrm{CO}_{2}, \mathrm{SO}_{2}$, and $\mathrm{NO}_{\mathrm{X}}$ emissions in the same period would predictively vastly abate with the scenarios, along with the anticipated remarkable decline in fossil energy consumptions, especially coal consumption. As a result, environmental welfare would vastly increase. Notably, it is highly conceivable that China could achieve its carbon emission peak at $12.4 \mathrm{GtCO}_{2}$ in 2028 when serving the comparatively most stringent low-carbon transformation pathway among the choices. This points out an effective way to accelerate the relatively most radical environmental improvement while moving the economy invariably forward. The double dividend effect identified adequately demonstrates that both economic growth and environmental improvement are sustainably gainable for the future with the low-carbon energy revolution. It demonstrates the low-carbon energy transformation as the necessary and feasible solution to achieve sustainable green development.

Most existing studies stressed that accelerating emissions mitigation and developing renewable energy would hurt economic development at the costs of elevating business expenditures and reducing the overall GDP (Shi et al., 2014; Mittal et al., 2016; Mi et al., 2017; Wang and Chen, 2019; Yuan et al., 2020). Apart from most previous studies, we, through this dedicated research, argue that it is highly feasible to achieve the double dividend effects of both economic growth and environmental improvement with low-carbon energy development. The key to realizing the target is that we must substantially boost low-carbon energy production and consumption to substitute the traditional fossil energy supply and demand structure. Upgrade to the new low-carbon production and consumption structure would be, on the one hand, exceedingly reduce wastes and carbon emissions, and, on the other hand, benefit the manufacturing by elevating energy utilization efficiency and reducing production cost for treating the waste emissions. Far more importantly, the new low-carbon technology would bring about the entire industrial structure's revolution, transforming the economy to green growth and sustaining societal development. Our result supports the expectation that the low-carbon energy transformation can produce the doubled dividends that would benefit both the economy and the environment. The investigation helps clarify the opacity in the debate of the relationship between economic growth and environmental improvement pertinent to low-carbon energy transformation.

\subsection{Issues in optimizing energy transformation}


The study reveals the feasibility of distinct valid energy transformation pathways for China's low-carbon development corresponding to the various implementation strategies. Aggregating all the strategies, including energy substitution and non-fossil power development, into the relatively strictest integrated solution can help achieve the grand target of peaking the nation's $\mathrm{CO}_{2}$ emissions by 2028. However, optimizing the energy structure, improving the electrification level, and a peak of carbon emission requires close attention and settlement to these barrier issues.

Optimizing energy structure and encouraging electricity development are the main contributors to the accomplishment of carbon peak and carbon neutrality, which requires China to achieve a higher level of electrification. In the future, renewable energy, especially wind power and solar power generation, should be the main force to support large-scale non-fossil energy, which is also consistent with the conclusion of European countries in achieving carbon neutrality. However, the accelerated development of renewable energy still confronts two challenges. First, renewable energy development is fragile to policy choices. Thus, it is crucial to remove barriers to renewable energy deployment and develop incentives to encourage investors and developers. Second, wind and solar electricity curtailment is the second most substantial challenge for renewable development. If China could not issue effective measures to reduce the curtailment, the investment in renewable energy would be wasteful at large, which would adversely affect the development of the renewable energy industry by reducing enterprises' profits and lowering investors' confidence. Moreover, the economic and environmental benefits articulated in this paper would not be possible to accomplish until all the renewable electricity capacity is thoroughly and efficiently in operation. Therefore, reducing the renewable electricity curtailment is of economic and environmental importance to China's sustainable development and low-carbon transformation.

Besides actively promoting electrification in terminal energy consumption, it is necessary to fulfill the power industry's decarbonization rapidly. One of the key challenges highlighted by the simulation results is that higher electrification holds a less positive impact on carbon emission reduction and energy structure transformation than the other targets. Non-fossil electricity accounts for half of the total power generation by 2030 . The carbon emission reduction effect brought by the reduction of fossil-fuel energy would be offset by increased coal-fired electricity consumption, with the demand for coal-fired power generation increasing due to its low cost. Therefore, as long as the higher electrification level target reaches, it is crucial to control the pace of electrification and decarbonization in the power sector to achieve carbon emission reduction, which may require the power sector planners and decisionmakers to strengthen policy coordination. Moreover, a few obstacles need to clear in improving electrification in China. For instance, analogous to the transport sector's electrification promotion policy, the policies about applying electric heating, cooling, and water heating technologies in the construction and electrification industries are far from sufficient and need particular attention and reinforcement.

\subsection{Possible actions towards the carbon peak and carbon neutrality}

Achieving the dual targets of carbon peak and carbon neutrality means that China's energy system will usher in an overall low-carbon transformation. China should eliminate the dependence on traditional fossil energy accompanying the continuous growth of energy consumption in such a short period, bringing the corresponding social costs. The target of achieving a carbon emissions peak in advance lays a solid foundation for carbon neutrality before 2060 . Thus, this study focuses on examining the impacts of low-carbon transformation to achieving the carbon peak target.

China should make great efforts to achieve carbon peak and carbon neutrality in the low-carbon transformation process. Firstly, the Chinese government needs to encourage fossil energy enterprises to adjust energy structure by gradually weakening fossil energy production and investment in clean energy such as renewable energy electricity,

Page $11 / 19$ 
energy storage, and electric vehicles. Secondly, the government should formulate relevant laws and regulations to urge state-owned enterprises to carry out comprehensive low-carbon transformation as soon as possible. Thirdly, it should give the energy enterprises corresponding policy supports such as tax incentives to the renewable energy and electric vehicle industries and appropriate subsidies to the transformative low-carbon energy technologies (e.g., CCUs and green hydrogen). Meanwhile, a market-oriented mechanism needs to be adopted to reduce the transformation cost and further enhance the competitiveness of low-carbon technology. Finally, to deepen the low-carbon of energy economy, China must accelerate the pace of reducing the proportion of coal consumption in energy structure in the next 10-30 years and improve the electrification level in each production sector. On the one hand, the roadmap of carbon peak and carbon neutrality, providing new driving forces for China's economic growth, will further promote economic structure, foster new investment, and create new employment opportunities. On the other hand, with carbon reduction, the air quality (e.g., $\mathrm{SO}_{2}$ and $\mathrm{NO}_{\mathrm{X}}$ ) in China will continue to improve, making China expected to achieve world standard air quality and sustainable development.

\section{Conclusions And Policy Implications}

Achieving low-carbon energy transformation is vital to coordinate economic growth and environmental improvement. However, existing studies have only explored one low-carbon transformation pathway, which failed to achieve the double dividend effect for the economy and environment, and rarely considered the importance of energy substitution for achieving low-carbon transformation. This paper develops three energy-target scenarios considering energy structure, electrification level, and carbon mitigation targets by 2030 announced by China's government. A dynamic CGE model, CHINAGEM, is applied to simulate and compare the economic and environmental implications among different pathways of China's low-carbon transformation. Based on the simulation results, we can obtain the following conclusions.

First, China's primary energy consumption and electricity production structure would substantially transfer to lowcarbon and clean under all three energy-target scenarios. The share of coal consumption decreases gradually, while the share of non-fossil energy gradually increases to $20.1 \%, 20.5 \%$, and $21.5 \%$ by 2030 under the three energy-target scenarios, respectively. Meanwhile, non-fossil energy power generation has gradually replaced coal-fired power generation. The share of non-fossil energy power generation in the power structure could achieve about $50 \%$ by 2030 under the same three scenarios.

Second, with the decline of fossil energy consumption, especially coal consumption, China's environment in 20202030 would improve a lot under the three energy-target scenarios. Compared with the baseline scenario, the total carbon emissions under the three scenarios expectably reduce significantly to $14.6,13.7$, and $12.3 \mathrm{GtCO}_{2}$ in 2030 , respectively, with an average annual growth rate of $3.18 \%, 2.70 \%$, and $1.64 \%$. Meantime, $\mathrm{SO}_{2}$ and $\mathrm{NO}_{\mathrm{x}}$ emissions would decrease by 24.9-34.1 million tons and 15.5-21.9 million tons by 2030. Most remarkably, a more stringent pathway by taking carbon mitigation measures will help China achieve the carbon emission peak of $12.4 \mathrm{GtCO}_{2}$ in

2028. From the perspective of carbon emission intensity, China's carbon emission per unit of GDP decreases rapidly under the three target scenarios.

Last, scenarios with different energy targets would achieve the different extent of double dividend effects. In scenario 1, only considering the regulation energy target, the economy has a slight increase, and the peak of $\mathrm{CO}_{2}$ emissions is unlikely to occur before 2030. In Scenario 2, it is evident that significant economic benefits are achievable, but the environmental benefits are still small. In scenario 3, real GDP and employment present the highest increases with $1.23 \%$ and $1.83 \%$, respectively, compared with other scenarios. The more stringent

Page $12 / 19$ 
pathway of low-carbon transformation will have remarkable environmental co-benefits by lowering $\mathrm{CO}_{2}, \mathrm{SO}_{2}$, and $\mathrm{NO}_{x}$ emissions.

To realize the double dividend benefits of the low-carbon transformation, the government must adopt efficient and timely policy measures to accelerate reducing coal and crude oil consumption, raising the utilization of renewable power generation, and adopting carbon mitigation measures. Various measures should apply to sustaining the mitigations in coal and crude oil consumption and prevent their unpleasant rebound. The measures consist of limiting the development of energy-intensive and high-pollution industries, improving the processing and conversion efficiency, resolving coal overcapacity, and eliminating backward coal capacity. Furthermore, China needs to promote renewable energy and electricity through various effective policies, e.g., accelerating the "coal to electricity" and "coal to gas" projects. Such policies afford subsidies and low-cost financing for renewable power grid connection and long-term transmission projects and increase the protective trading quota for electricity generated with renewable resources. More efforts should strengthen the development and application of advanced low-carbon technology and promote the carbon mitigation policies like the carbon trading system and carbon tax. Most importantly, it calls for more integrated planning and policy measures for realizing the coordinative and sustainable development of the economy-environment system under the dual targets of carbon peak and carbon neutrality.

\section{Declarations}

\section{Ethics approval}

Not applicable.

\section{Consent to participate}

Not applicable.

\section{Consent to publish}

Not applicable.

\section{Availability of data and materials}

Not applicable.

\section{Competing interests}

The authors declare that they have no competing interests.

\section{Funding}

This work was supported by the National Natural Science Foundation of China [Grant No. 71903014].

\section{Authors' contributions}

Ling He performed literature study, data analysis and technical writing. Bangpei Wang wrote the initial draft of the manuscript. Wanting Xu performed literature study. Hao Chen and Qi Cui supervised the results and data analysis and performed the technical revisions of the manuscript. All authors read and approved the final manuscript. 


\section{Corresponding author}

Correspondence to Hao Chen.

\section{References}

Capuano, L. (2018). International energy outlook 2018 (IEO2018). US Energy Information Administration (EIA): Washington, DC, USA, 2018, 21.

Change, I. P. O. C. (2006). 2006 IPCC guidelines for national greenhouse gas inventories. Institute for Global Environmental Strategies, Hayama, Kanagawa, Japan.

Chen, H., He, L., Chen, J., Yuan, B., Huang, T., Cui, Q., (2019). Impacts of clean energy substitution for polluting FossilFuels in terminal energy consumption on the economy and environment in China. Sustainability (Switzerland) 11. https://doi.org/10.3390/su11226419

Chi, Y., Guo, Z., Zheng, Y., Zhang, X., (2014). Scenarios analysis of the energies' consumption and carbon emissions in china based on a dynamic CGE model. Sustainability (Switzerland) 6, 487-512.

https://doi.org/10.3390/su6020487

Cui, L., Li, R., Song, M., Zhu, L., (2019). Can China achieve its 2030 energy development targets by fulfilling carbon intensity reduction commitments? Energy Economics 83, 61-73. https://doi.org/10.1016/j.eneco.2019.06.016

Cui, Q., He, L., Liu, Y., Zheng, Y., Wei, W., Yang, B., Zhou, M., (2021). The impacts of COVID-19 pandemic on China's transport sectors based on the CGE model coupled with a decomposition analysis approach. Transport Policy 103, 103-115. https://doi.org/10.1016/j.tranpol.2021.01.017

Cui, Q., Liu, Y., Ali, T., Gao, J., Chen, H., (2020). Economic and climate impacts of reducing China's renewable electricity curtailment: A comparison between CGE models with alternative nesting structures of electricity. Energy Economics 91, 104892. https://doi.org/10.1016/j.eneco.2020.104892

Dai, H., Xie, X., Xie, Y., Liu, J., Masui, T., (2016). Green growth: The economic impacts of large-scale renewable energy development in China. Applied Energy 162, 435-449. https://doi.org/10.1016/j.apenergy.2015.10.049

Duan, H., Mo, J., Fan, Y., Wang, S., (2018). Achieving China's energy and climate policy targets in 2030 under multiple uncertainties. Energy Economics 70, 45-60. https://doi.org/10.1016/j.eneco.2017.12.022

ERI (Energy Research Institute NDRC), CNREC (China National of Renewable Energy Centre). (2017). China Renewable Energy Outlook 2017 (CREO2017). Accessed at: https://news.bjx.com.cn/html/20181019/935389.shtml

ERI (Energy Research Institute NDRC), CNREC (China National of Renewable Energy Centre). (2018). China Renewable Energy Outlook 2018 (CREO2018). Accessed at: http://www.china-nengyuan.com/news/130433.html

He, Y., Lin, B., (2018). Forecasting China's total energy demand and its structure using ADL-MIDAS model. Energy 151, 420-429. https://doi.org/10.1016/j.energy.2018.03.067

Huang, M.-T., Zhai, P.-M., (2021). Achieving Paris Agreement temperature goals requires carbon neutrality by middle century with far-reaching transitions in the whole society. Advances in Climate Change Research 0-5. https://doi.org/10.1016/j.accre.2021.03.004 
Khanna, N., Fridley, D., Zhou, N., Karali, N., Zhang, J., Feng, W., (2019). Energy and $\mathrm{CO}_{2}$ implications of decarbonization strategies for China beyond efficiency: Modeling 2050 maximum renewable resources and accelerated electrification impacts. Applied Energy 242, 12-26. https://doi.org/10.1016/j.apenergy.2019.03.116

Li, J.F., Ma, Z.Y., Zhang, Y.X., Wen, Z.C., (2018). Analysis on energy demand and $\mathrm{CO}_{2}$ emissions in China following the Energy Production and Consumption Revolution Strategy and China Dream target. Advances in Climate Change Research 9, 16-26. https://doi.org/10.1016/j.accre.2018.01.001

Li, K., Fang, L., He, L., (2019). How population and energy price affect China's environmental pollution? Energy Policy 129, 386-396. https://doi.org/10.1016/j.enpol.2019.02.020

Lin, B., Agyeman, S.D., (2019). Assessing Ghana's carbon dioxide emissions through energy consumption structure towards a sustainable development path. Journal of Cleaner Production 238, 117941.

https://doi.org/10.1016/j.jclepro.2019.117941

Liu, Q., Lei, Q., Xu, H., Yuan, J., (2018). China's energy revolution strategy into 2030. Resources, Conservation and Recycling 128, 78-89. https://doi.org/10.1016/j.resconrec.2017.09.028

Liu, Q., Zhang, W., Yao, M., Yuan, J., (2017). Carbon emissions performance regulation for China's top generation groups by 2020: Too challenging to realize? Resources, Conservation and Recycling 122, 326-334.

https://doi.org/10.1016/j.resconrec.2017.03.008

Lv, Z., Xu, T., (2019). Trade openness, urbanization and CO 2 emissions: Dynamic panel data analysis of middleincome countries. Journal of International Trade and Economic Development 28, 317-330.

https://doi.org/10.1080/09638199.2018.1534878

Ma, J. P., (2019). Empirical Research on Economic and Climate Effects of Low Carbon Transition Policy. Yuejiang Academic Journal 11, 43-56+119-120. https://doi.org/10.13878/j.cnki.yjxk.2019.03.006

Mai, Y., Dixon, P.B., Riimmer, M., (2010). A Monash-Styled Dynamic CGE Model of China 53.

Mallapaty, S., (2020). How China could be carbon neutral by mid-century. Nature 586, 482-483.

https://doi.org/10.1038/d41586-020-02927-9

Mi, Z., Wei, Y.M., Wang, B., Meng, J., Liu, Z., Shan, Y., Liu, J., Guan, D., (2017). Socioeconomic impact assessment of China's $\mathrm{CO}_{2}$ emissions peak prior to 2030. Journal of Cleaner Production 142, 2227-2236.

https://doi.org/10.1016/j.jclepro.2016.11.055

Mittal, S., Dai, H., Fujimori, S., Masui, T., (2016). Bridging greenhouse gas emissions and renewable energy deployment target: Comparative assessment of China and India. Applied Energy 166, 301-313. https://doi.org/10.1016/j.apenergy.2015.12.124

Monjardino, J., Dias, L., Fortes, P., Tente, H., Ferreira, F., Seixas, J., (2021). Carbon neutrality pathways effects on air pollutant emissions: The Portuguese case. Atmosphere 12. https://doi.org/10.3390/atmos12030324

Mu, Y., Cai, W., Evans, S., Wang, C., Roland-Holst, D., (2018). Employment impacts of renewable energy policies in China: A decomposition analysis based on a CGE modeling framework. Applied Energy 210, 256-267.

https://doi.org/10.1016/j.apenergy.2017.10.086

Page 15/19 
NDRC (National Development and Reform Commission). (2016a). 13th Five-Year Energy Development Plan. Accessed at: http://www.ndrc.gov.cn/zcfb/zcfbtz/201612/t20161216_830264.html.

NDRC (National Development and Reform Commission). (2016b). Energy Production and Consumption Revolution Strategy (2016-2030). Accessed at: https://www.ndrc.gov.cn/fggz/fzzlgh/gjjzxgh/201705/t20170517_1196767.html.

Rajbhandari, S., Limmeechokchai, B., (2020). Assessment of greenhouse gas mitigation pathways for Thailand towards achievement of the $2^{\circ} \mathrm{C}$ and $1.5^{\circ} \mathrm{C}$ Paris Agreement targets. Climate Policy $0,1-22$.

https://doi.org/10.1080/14693062.2020.1857218

Shi, M., Zhou, S., Li, N., Yuan, Y., (2014). Prospect for China's medium and long-term economic development under energy supply constraint. Journal of Systems Engineering 29, 602-611.

https://doi.org/10.13383/j.cnki.jse.2014.05.004

Su, C., Urban, F., (2021). Circular economy for clean energy transitions: A new opportunity under the COVID-19 pandemic. Applied Energy 289, 116666. https://doi.org/10.1016/j.apenergy.2021.116666

Wang, H., Chen, W., (2019). Modeling of energy transformation pathways under current policies, NDCs and enhanced NDCs to achieve 2-degree target. Applied Energy 250, 549-557. https://doi.org/10.1016/j.apenergy.2019.05.009

Wang, H., Chen, Z., Wu, X., Nie, X., (2019). Can a carbon trading system promote the transformation of a low-carbon economy under the framework of the porter hypothesis? -Empirical analysis based on the PSM-DID method. Energy Policy 129, 930-938. https://doi.org/10.1016/j.enpol.2019.03.007

Wu凶Fan, (2017). China's Energy Consumption Projection Prediction Restrained by Economic Transition and Low Carbon Emission. Economy and Management 31, 80-86.

Xiong, J., Xu, D., (2021). Relationship between energy consumption, economic growth and environmental pollution in China. Environmental Research 194, 110718. https://doi.org/10.1016/j.envres.2021.110718

Yuan, Y., Duan, H., Tsvetanov, T.G., (2020). Synergizing China's energy and carbon mitigation goals: General equilibrium modeling and policy assessment. Energy Economics 89, 104787.

https://doi.org/10.1016/j.eneco.2020.104787

Yu, S., Zheng, S., Li, X., (2018). The achievement of the carbon emissions peak in China: The role of energy consumption structure optimization. Energy Economics 74, 693-707. https://doi.org/10.1016/j.eneco.2018.07.017

Zhou, N., Price, L., Yande, D., Creyts, J., Khanna, N., Fridley, D., Lu, H., Feng, W., Liu, X., Hasanbeigi, A., Tian, Z., Yang, H., Bai, Q., Zhu, Y., Xiong, H., Zhang, J., Chrisman, K., Agenbroad, J., Ke, Y., McIntosh, R., Mullaney, D., Stranger, C., Wanless, E., Wetzel, D., Yee, C., Franconi, E., (2019). A roadmap for China to peak carbon dioxide emissions and achieve a $20 \%$ share of non-fossil fuels in primary energy by 2030. Applied Energy 239, 793-819.

https://doi.org/10.1016/j.apenergy.2019.01.154

Zhou, S., Tong, Q., Pan, X., Cao, M., Wang, H., Gao, J., Ou, X., (2021). Research on low-carbon energy transformation of China necessary to achieve the Paris agreement goals: A global perspective. Energy Economics 95, 105137. https://doi.org/10.1016/j.eneco.2021.105137 


\section{Total output}

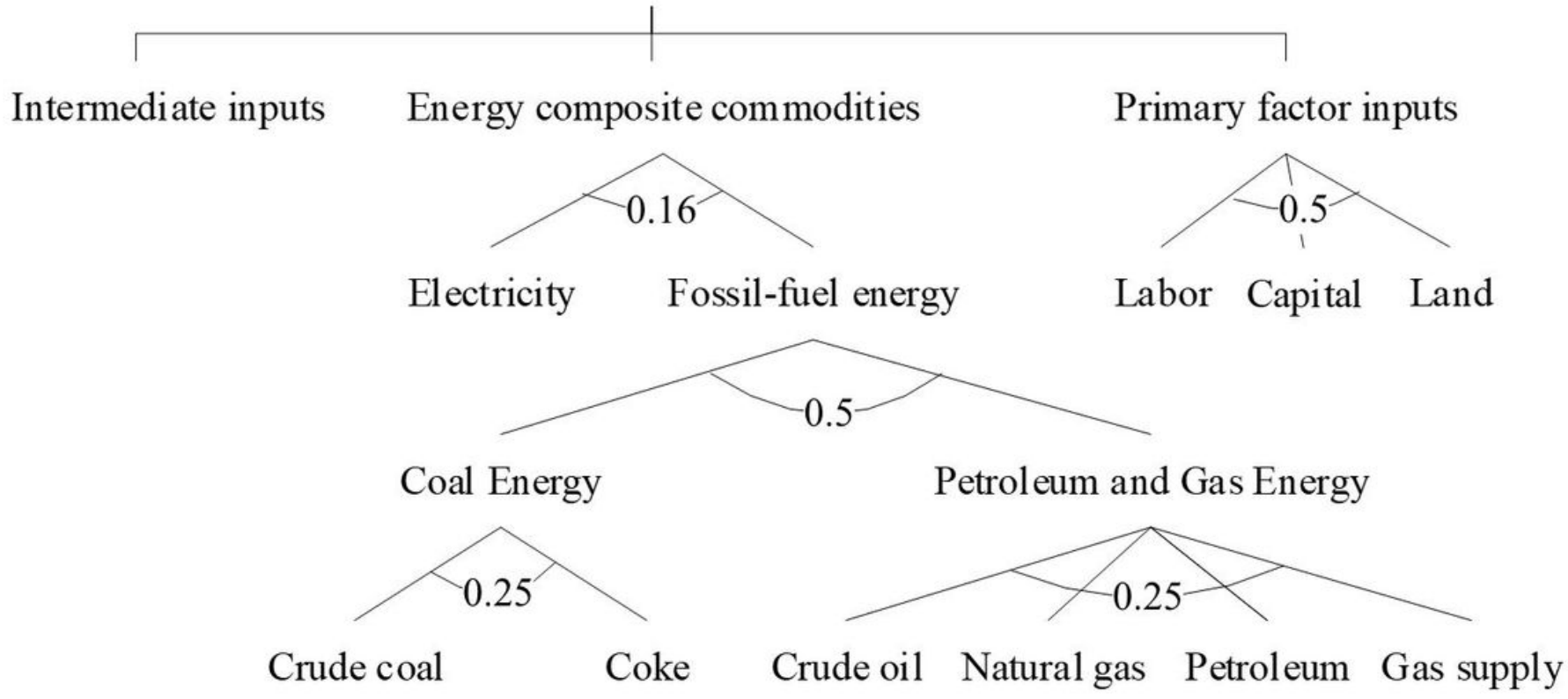

Figure 1

The nested structure of energy products for production sectors

\section{Electricity}

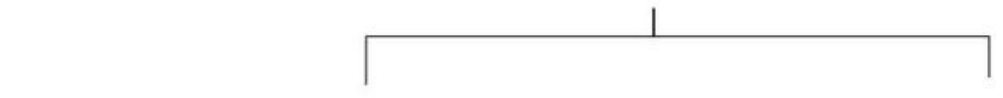

Generation Transmission and distribution

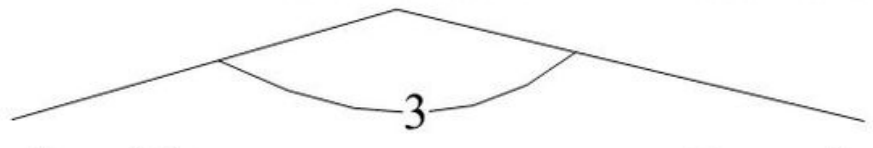

Stable electricity

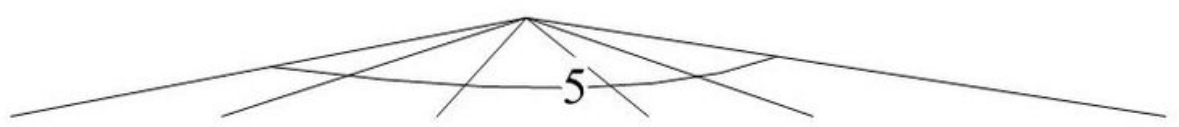

Coal-fired Oil-fired Gas-fired Nuclear Hydro Bio. and Geo. Wind Solar

\section{Figure 2}

The nested structure of electricity consumption for production sectors 


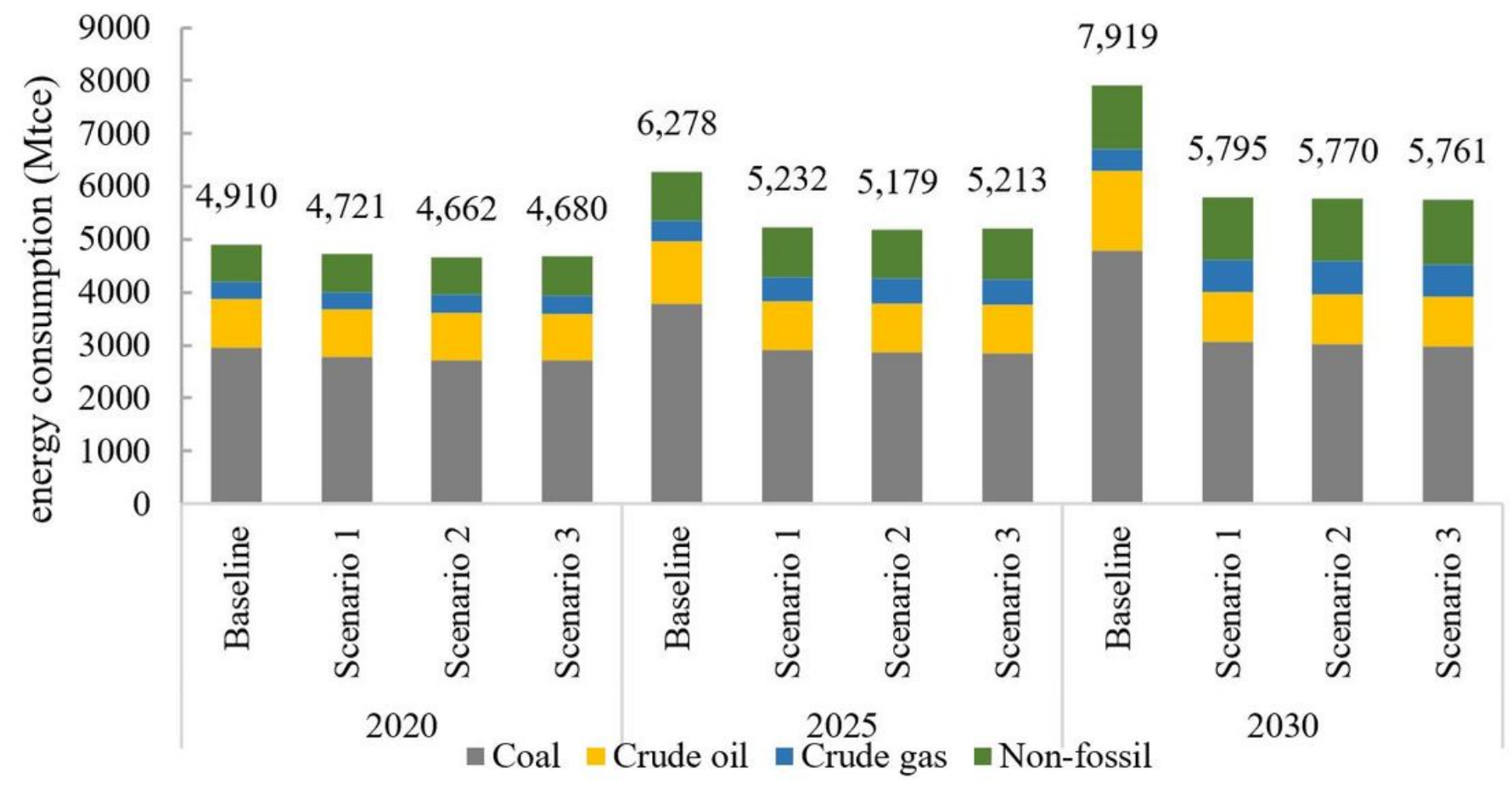

Figure 3

China's primary energy consumption under different scenarios. Source: CHINAGEM model

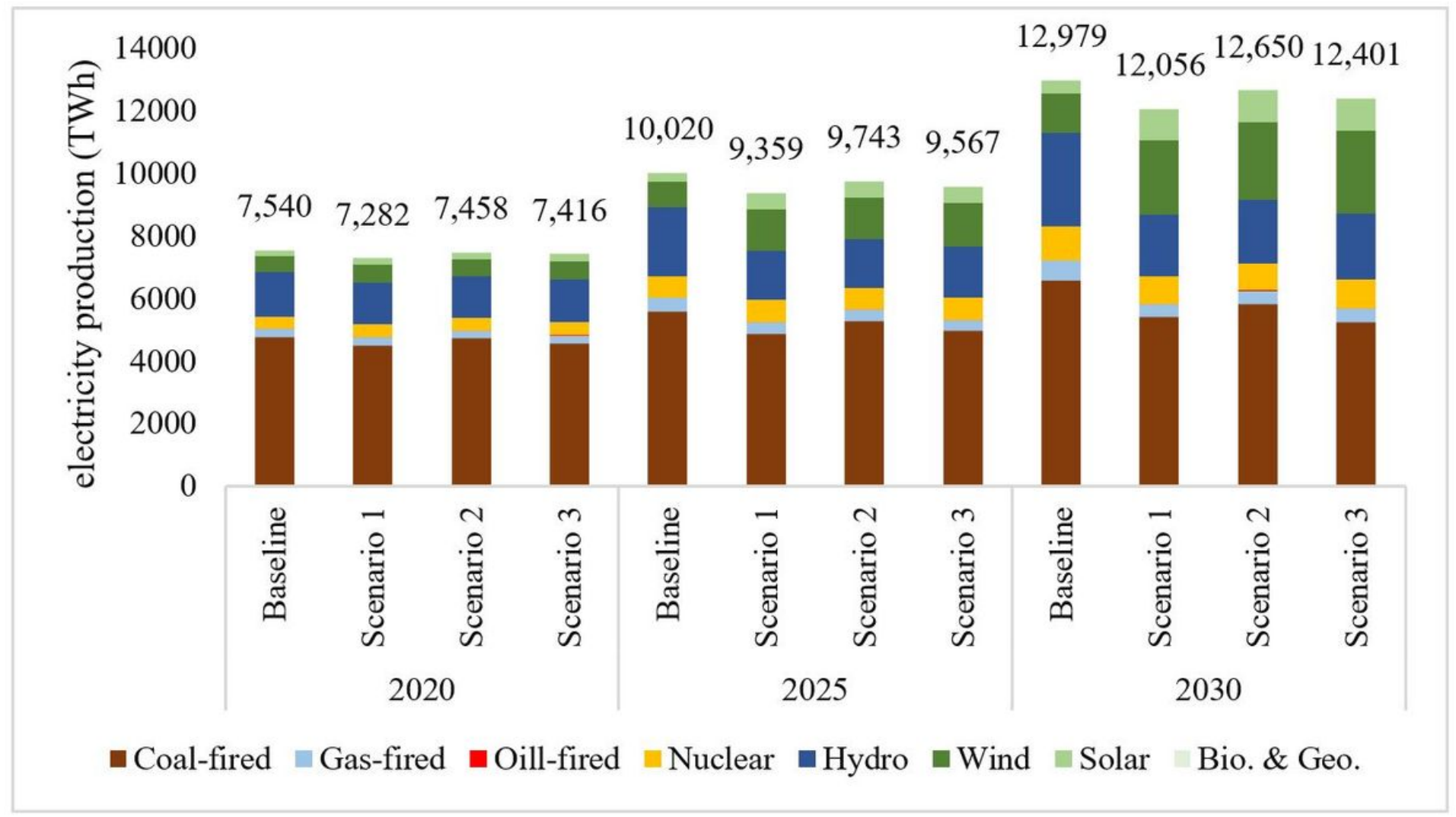

Figure 4 

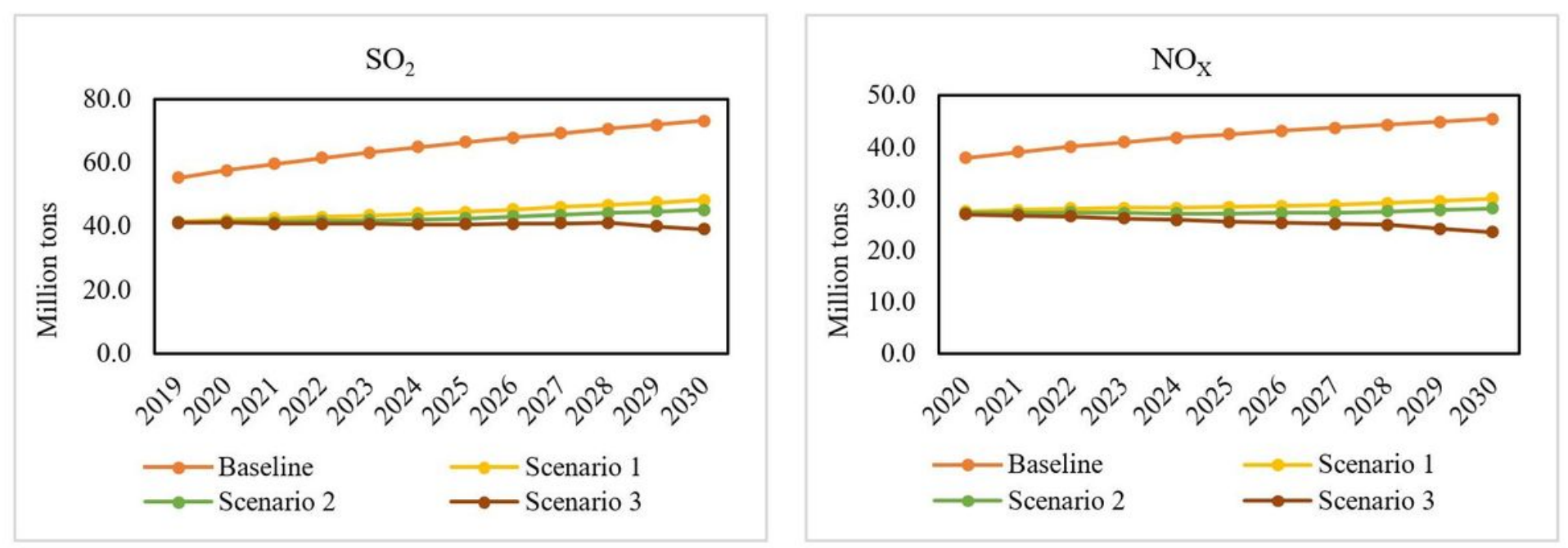

\section{Figure 5}

China's SO2 and NOX emissions in 2020-2030 under different scenarios (Million tons). Source: CHINAGEM model

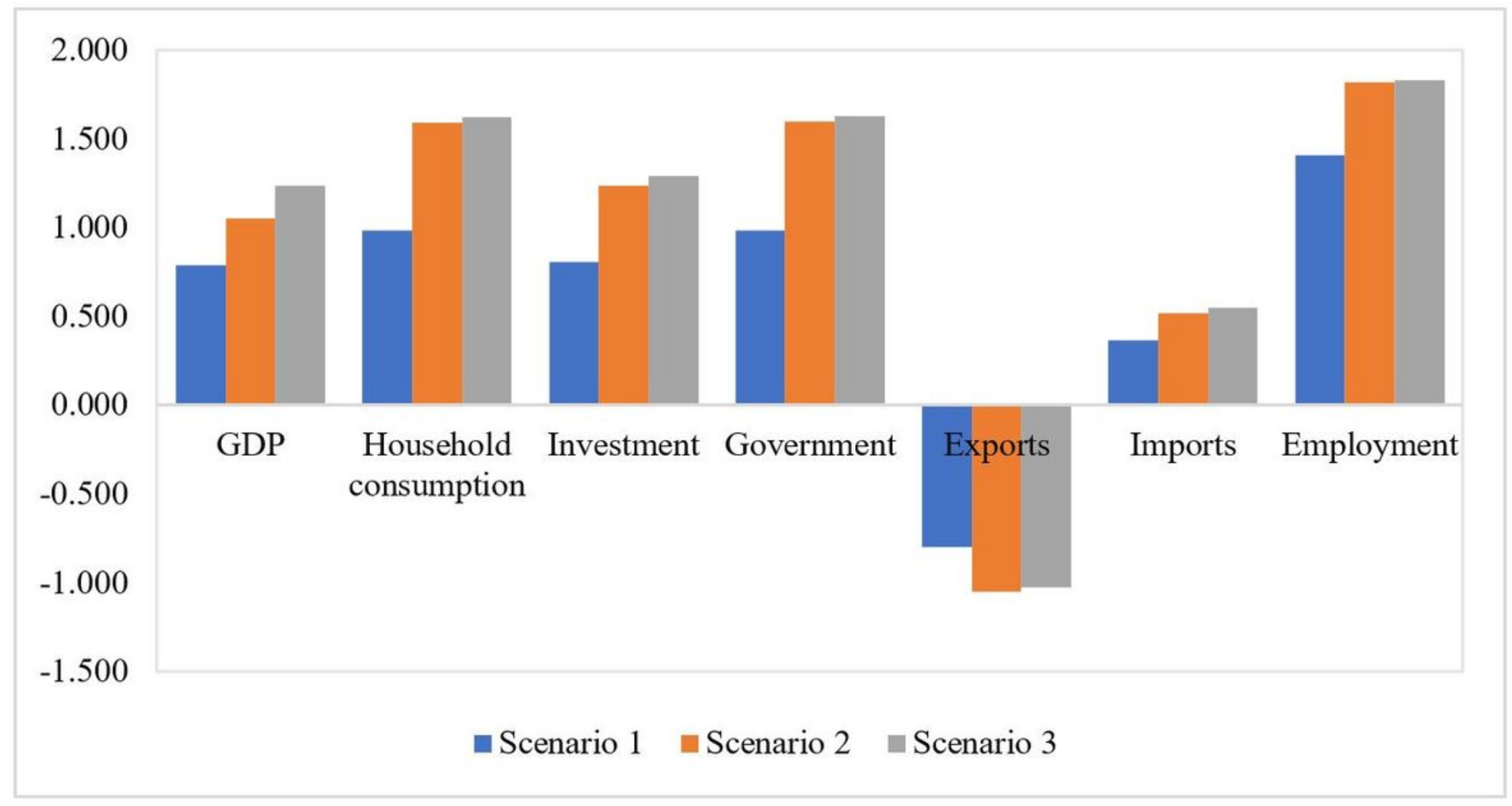

Figure 6

Impacts on the macro-economy in 2020-2030 under different energy-target scenarios (\%). Source: CHINAGEM model 